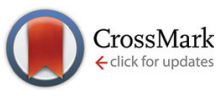

Cite this: Org. Biomol. Chem., 2016, 14,4199

Received 25th March 2016, Accepted 15th April 2016

DOI: $10.1039 / c 6 o b 00640 j$

www.rsc.org/obc

\section{The total synthesis and functional evaluation of fourteen stereoisomers of yaku'amide B. The importance of stereochemistry for hydrophobicity and cytotoxicity $\dagger$}

\author{
Hiroyuki Mutoh, Yusuke Sesoko, Takefumi Kuranaga, \$ Hiroaki Itoh and \\ Masayuki Inoue*
}

\begin{abstract}
Yaku'amide B is a highly unsaturated linear tridecapeptide and an extremely potent cytotoxin. Herein, we describe the synthesis of fourteen new stereoisomers of yaku'amide B using a unified assembly strategy. The hydrophobicities and cytotoxicities of these analogues were analyzed, along with those of four previously prepared isomers. Although all of the analogues share a common planar structure, their $\log D$ values varied significantly (3.39-5.32), presumably reflecting their distinct three-dimensional shapes. Subnanomolar-level cytotoxicity was observed for the natural yaku'amide B and its epimer of the N-terminal acyl group, whereas the other sixteen isomers exhibited 13- to 1200-fold weaker activities than that of the natural isomer. These data indicated the importance of the overall stereostructure of the 13-mer sequence of yaku'amide $B$ for exerting its potent toxicity.
\end{abstract}

\section{Introduction}

Yaku'amides A (1) and B (2) were isolated from a deep sea sponge Ceratopsion sp. (Fig. 1) and were reported to exhibit exceptionally potent cytotoxicity towards P388 murine leukemia cells. ${ }^{1}$ Cytotoxicity assays of $\mathbf{1}$ using a panel of 39 human cancer cell lines (JFCR39) ${ }^{2}$ unveiled its distinct growth-inhibitory profile in comparison with 38 clinically available anticancer drugs, suggesting its potentially novel mode of action. The linear tridecapeptide sequences of $\mathbf{1}$ and $\mathbf{2}$ only differ in their third residue (Gly-3 for $\mathbf{1}$ and Ala-3 for 2), and both compounds contain four tetrasubstituted $\alpha, \beta$-dehydroamino acids ${ }^{3}$ ( $\Delta$ Ile-2, $\Delta$ Ile-4, $\Delta$ Ile-9, and $\Delta$ Val-13) and seven other nonproteinogenic amino acids. Additionally, an N-terminal acyl (NTA) group and a C-terminal amine (CTA) cap the $\mathrm{N}$ - and C-termini,

Graduate School of Pharmaceutical Sciences, The University of Tokyo, 7-3-1 Hongo, Bunkyo-ku, Tokyo 113-0033, Japan. E-mail: inoue@mol.f.u-tokyo.ac.jp;

Fax: +81 3-5841-0568

$\dagger$ Electronic supplementary information (ESI) available: Experimental procedures and assay data. See DOI: $10.1039 / \mathrm{c} 60 \mathrm{ob} 00640 \mathrm{j}$

¥Current address: Faculty of Pharmaceutical Sciences, Hokkaido University, Kita 12-jo Nishi 6-chome, Kita-ku, Sapporo, 060-0812, Japan. respectively. These unusual structural features and potent biological activities of $\mathbf{1}$ and $\mathbf{2}$ have spurred interest in the chemical and biological communities. ${ }^{4}$

Since only minute amounts of $\mathbf{1}$ and $\mathbf{2}$ have been obtained from natural sources (1: $1.3 \mathrm{mg} ; 2: 0.3 \mathrm{mg}$ ), their structural determination is incomplete and detailed biological studies have been hampered. To address these issues, we launched synthetic studies of $\mathbf{1}$ and $\mathbf{2}$ as the initial phase for further investigations of their structures and bioactivities. Consequently, the C4-epimers of the NTA moiety of the proposed structures $1 \mathbf{1} / \mathbf{b}$ and $2 \mathbf{a} / \mathbf{b}$ were chemically constructed by developing a new protocol for construction of the $\alpha, \beta$-unsaturated amino acid residues. ${ }^{5,6}$ Namely, Cu-catalyzed $\mathrm{C}\left(\mathrm{sp}^{2}\right)-\mathrm{N}$ bond formation between the primary amides and the alkenyl iodides was adopted to construct four building blocks with the tetrasubstituted enamide moieties (4a, 5a, 9, and 10a). ${ }^{7}$ Then, the enamide building blocks and the protected amino acids were condensed stepwise to furnish the possible proposed structures $\mathbf{1 a} / \mathbf{b}$ and $\mathbf{2 a} / \mathbf{b}$. However, both the NTA-epimers $\mathbf{1 a} / \mathbf{b}$ and 2a/b exhibited different chromatographic behaviors from naturally occurring 1 and 2, respectively. This finding prompted investigations directed toward determining the true structures of $\mathbf{1}$ and 2. Structural information was gathered through degradative studies of $0.05 \mathrm{mg}$ of the available 2 and synthetic preparation of all the possible structures of the degraded partial structures. These studies allowed us to establish the structures of the natural 1 and 2 to be $1 \mathrm{c}$ and $2 \mathrm{c}$. Both the revised structures possess the inverse configurations at the $\mathrm{C}_{\alpha^{-}}$ positions of the four amino acid residues (OHVal-7, -8, Val-11, and -12) of the proposed structures, and the $S$-configuration at C4 of NTA. Compounds $1 \mathbf{c}$ and $2 \mathbf{c}$ were then prepared by total syntheses to confirm their structural authenticity.

During the process of structural revision by a combination of degradation and synthesis, the total syntheses of the multiple potential isomers of the natural 2 were independently performed without achieving the revised structure 2c. Specifically, the fourteen analogues 2e-r having different amino acid stereochemistries from those of the proposed structures $2 \mathbf{a} / \mathbf{b}$ 


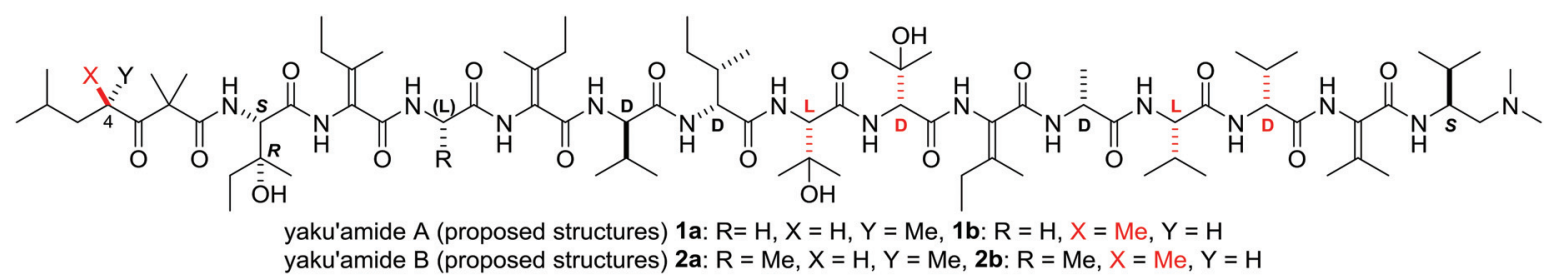

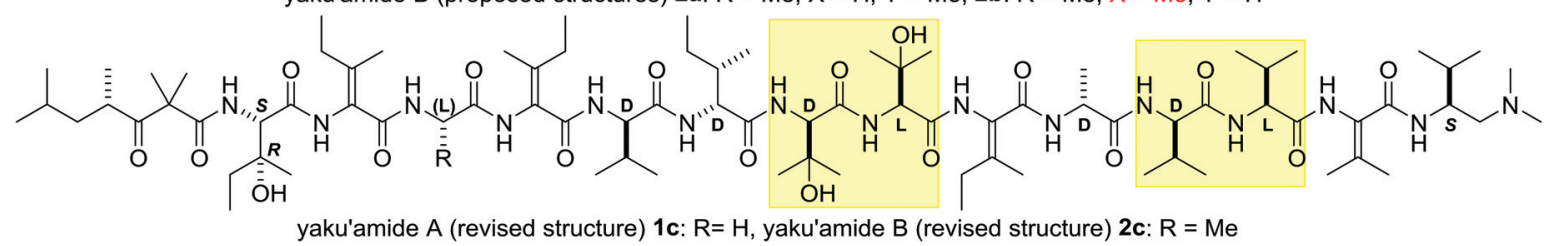<smiles>CCC(C)=C(NC(=O)[C@H](NC(=O)C(C)(C)C(=O)C(C)CC(C)C)C(C)(O)CC)C(=O)NC(C)C(=O)NC(C(=O)NC(C(=O)NC(C(=O)NC(C(=O)NC(C(=O)NC(C(=O)NC(C)C(=O)NC(C(=O)NC(C(=O)NC(C(=O)NC(CN(C)C)C(C)C)C(C)C)C(C)C)C(C)C)C(C)C)C(C)C)C(C)(C)O)C(C)C)C(C)C)C(C)(C)O</smiles>

NTA OHlle-1 $\Delta$ lle-2 Ala-3 $\Delta$ lle-4 Val-5 lle-6 OHVal-7 OHVal-8 $\Delta$ lle-9 Ala-10 Val-11 Val-12 $\Delta$ Val-13 CTA

\begin{tabular}{cccccccccccc}
\hline compound & NTA & OHlle-1 & Ala-3 & Val-5 & lle-6 & OHVal-7 & OHVal-8 & Ala-10 & Val-11 & Val-12 & CTA \\
\hline 2a & S & $2 S, 3 R$ & L & D & D-allo & L & D & D & L & D & S \\
2b & $R$ & $2 S, 3 R$ & L & D & D-allo & L & D & D & L & D & S \\
2c & S & $2 S, 3 R$ & L & D & D-allo & D & L & D & D & L & S \\
2d & $R$ & $2 S, 3 R$ & L & D & D-allo & D & L & D & D & L & S
\end{tabular}

newly synthesized analogues

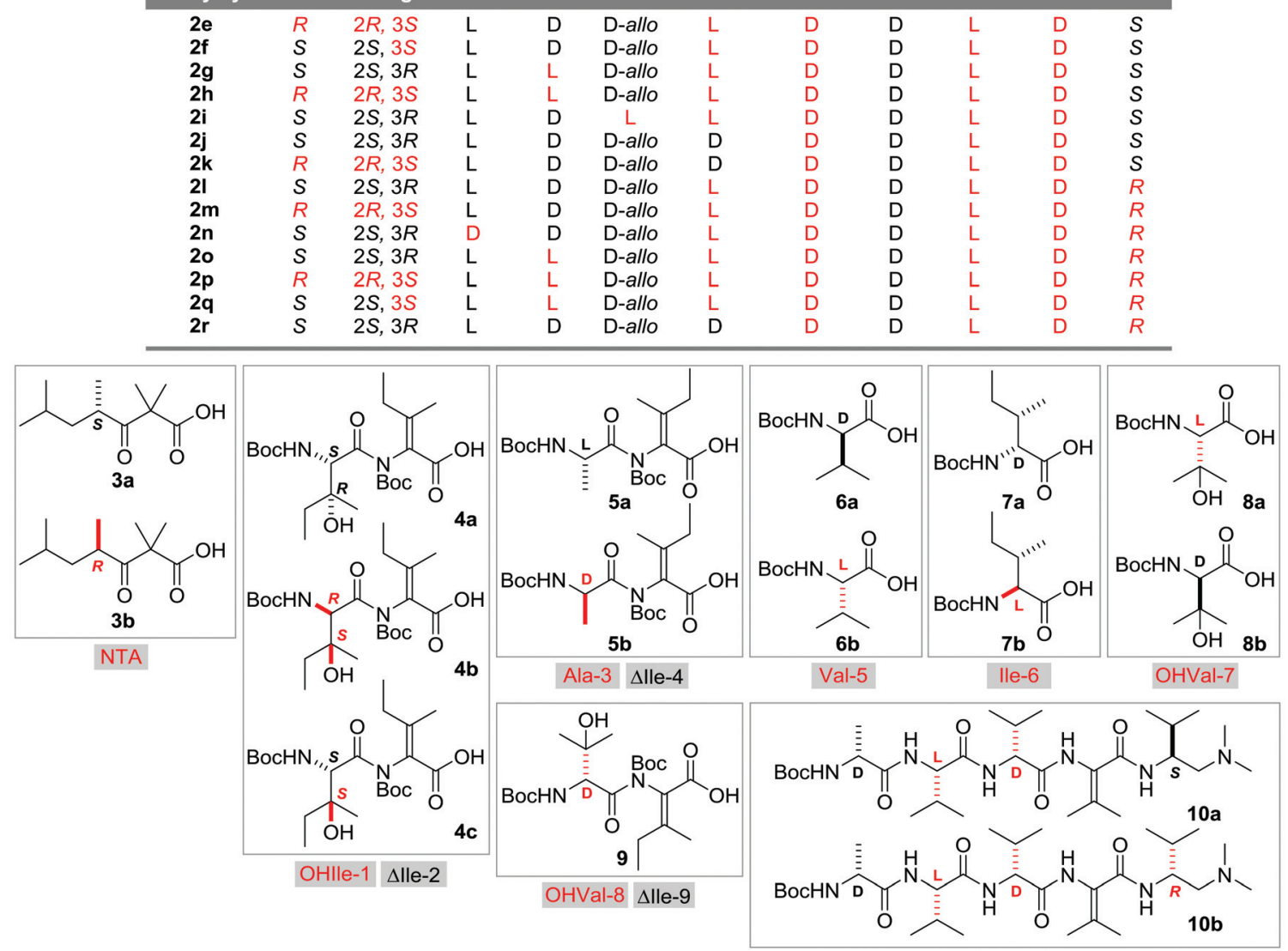

Ala-10 Val-11 Val-12 $\Delta$ Val-13 CTA

Fig. 1 Structures of 1a/b (yaku'amide A proposed structures), 1c (yaku'amide A revised structure), 2a/b (yaku'amide B proposed structures), 2c (yaku'amide B revised structure), 2d (NTA-epimer of yaku'amide B), newly synthesized analogues 2e-r, and the synthetic fragments 3-10. The bonds displayed in red indicate the altered stereochemistry from the natural $2 \mathrm{c}$. Boc $=$ tert-butoxycarbonyl; $\Delta$ lle $=\alpha, \beta$-dehydroisoleucine; $\Delta$ Val $=$ $\alpha, \beta$-dehydrovaline; OHIle $=\beta$-hydroxyisoleucine; $\mathrm{OHVal}=\beta$-hydroxyvaline. 
were synthesized. Upon analysis by ultrahigh-performance liquid chromatography (UHPLC), all of the analogues $2 \mathbf{e}-\mathbf{r}$ provided retention times distinct from that of the natural 2 , indicating that they did not correspond to the true structure. Although the syntheses of $2 \mathbf{e}-\mathbf{r}$ did not contribute to the structural elucidation of $\mathbf{2 c}$, this focused library of stereoisomers provided us with a valuable opportunity for investigating the structure-activity relationship (SAR) of yaku'amide B (2c). ${ }^{8}$ Compounds 2e-r share the same planar structure and thus their functional evaluations would clarify the stereochemical requirement of the amino-acid residues for the unique physicochemical and potent biological properties of 2c. Furthermore, the SAR study would offer useful insight into the unknown mode of action of 2c. Herein, we report the syntheses and functional analyses of the fourteen analogues $2 \mathbf{e}-\mathbf{r}$ of yaku'amide B (2c). These studies showed that the configurational changes of the main chain of $2 c$ significantly affected the hydrophobicities and greatly diminished the cytotoxicities. Only 2c and its C4-epimer of NTA 2d displayed subnanomolarlevel cytotoxicity towards P388 cells, demonstrating the biological importance of the main chain stereochemistry.

\section{Results and discussion}

The fourteen new analogues of yaku'amide B, 2e-r, have different configurations from the natural 2c at NTA, OHIle-1, Ala-3, Val-5, Ile-6, OHVal-7, OHVal-8, Val-11, Val-12, and/or CTA (Fig. 1), while the double-bond geometries of $\Delta$ Ile-2, -4 , and -9 and the D-stereochemistry of Ala-10 are retained. As 2e-r were designed based on the proposed structures $2 \mathbf{a} / \mathbf{b}$, all of these peptides possess the same stereochemistries at OHVal-8, Val-11, and Val-12. We previously reported the total syntheses of $1 \mathbf{a}-\mathbf{c}$ and $\mathbf{2 a - d}$ by assembling eight building blocks. This efficient strategy was applied to the syntheses of $2 \mathbf{e}-\mathbf{r}$ by switching the fragments to their corresponding stereoisomers. Accordingly, sixteen fragments were necessary for the construction of 2e-r (NTA: 3a and 3b; OHIle-1- $\Delta$ Ile-2: $\mathbf{4 a}, \mathbf{4 b}$, and $4 \mathbf{c}$; Ala-3- $\Delta$ Ile-4: 5a and 5b; Val-5: $6 \mathbf{a}$ and 6b; Ile-6: 7a and 7b; OHVal-7: 8a and 8b; OHVal-8- $\Delta$ Ile-9: 9; Ala-10-Val-11-Val-12$\Delta$ Val-13-CTA: 10a and 10b). While 3a/b, 4a, 5a, 6a/b, 7a/b, 8a/b, 9 and $10 a / b$ were previously prepared on the way toward the total synthesis and structural elucidation of $\mathbf{1 c}$ and $2 \mathbf{c}{ }^{5}$ dipeptides $\mathbf{4 b}$ (enantiomer of $\mathbf{4 a}$ ), $\mathbf{4 c}$ (diastereomer of $\mathbf{4 a}$ ) and $\mathbf{5 b}$ (enantiomer of 5a) were newly obtained by using Cu-mediated $\mathrm{C}\left(\mathrm{sp}^{2}\right)-\mathrm{N}$ bond formation from the corresponding monomers. ${ }^{9}$

To produce the analogues $\mathbf{2 e - r}$, the sixteen synthetic fragments were condensed according to the assembly procedure that was optimized for the route to $2 \mathbf{a}$ and $2 \mathbf{b}^{5 a}$ (Scheme 1). The unified total syntheses of the known $2 \mathbf{a} / \mathbf{b}$ and the new $2 \mathbf{e}-\mathbf{r}$ started with the TFA-promoted removal of the $N_{\alpha}$-Boc group from 4-mer derivatives 10a and 10b. The obtained two amines were separately treated with carboxylic acid $\mathbf{9}$ in the presence of PyBOP ${ }^{10} /$ HOAt $^{11}$ to generate the protected 6-mer peptides 11a and 11b, respectively. Detachment of the two Boc groups of OHVal-8 and $\Delta$ Ile-9 of 11a and 11b with TFA afforded the corresponding amines, which were amidated with $\mathbf{8 a}$ or $\mathbf{8 b}$ by the action of COMU, ${ }^{12}$ giving rise to the four 7-mer derivatives $\mathbf{1 2 a} / \mathbf{b}$ and $\mathbf{1 2 c} / \mathbf{d}$, respectively. Stepwise elongation from $\mathbf{1 2 a}-\mathbf{d}$ using the five building blocks completed the syntheses of $2 \mathbf{a}$ / b/e-r. Namely, two cycles of TFA-mediated $N_{\alpha}$-deprotection and COMU-promoted condensation using $7 \mathbf{a} / \mathbf{b}$ and $\mathbf{6 a} / \mathbf{b}$ converted 12a-d to the seven 9-mer peptides $(\mathbf{1 2 a}-\mathbf{d} \rightarrow \mathbf{1 3 a} \mathbf{a} \rightarrow$ 14a-g). The obtained compounds $14 \mathbf{a}-\mathbf{g}$ were then transformed to fifteen 13-mer peptides 16a-o through repeated Boc removal and PyBOP/HOAt-promoted conjugation using $5 \mathbf{a} / \mathbf{b}$ or 4a-c $(14 a-g \rightarrow 15 a-h \rightarrow 16 a-o)$. Finally, COMU enabled the coupling of the NTA unit $3 \mathbf{a} / \mathbf{b}$ with $16 \mathbf{a}-\mathbf{o}$, delivering the sixteen yaku'amide analogues $\mathbf{2 a}, \mathbf{2 b}$, and $2 \mathbf{e}-\mathbf{r}$. As a result of the present divergent synthesis, the fourteen new peptides $2 \mathbf{e}-\mathbf{r}$ were efficiently constructed in 14 steps from 9 in reasonable yields (2a, 2b, 2e, 2f, 2g, 2h, 2i, 2j, 2k, 2l, 2m, 2n, 2o, 2p, 2q, and $2 \mathrm{r}$ for 14, 11, 9.5, 8.7, 11, 9.5, 4.8, 3.4, 5.9, 4.2, 10, 12, 7.0, $14,6.6$, and $3.5 \%$, respectively). These achievements corroborated the high adaptability of our synthetic strategy for the preparation of diverse yaku'amide isomers.

The completion of the total syntheses of $2 \mathbf{a}-\mathbf{d}$ and the fourteen new analogues $2 \mathbf{e}-\mathbf{r}$ permitted us to conduct systematic functional analyses. Since the overall hydrophobicity influences the molecular behavior and interaction with the cell membrane and biomolecules, it is one of the most critical factors affecting the biological activity of a compound. Accordingly, the hydrophobicities of isomers $2 \mathbf{a}-\mathbf{r}$ were estimated by determination of their octanol/water distribution coefficients $(\log D) .{ }^{13}$ To calculate the $\log D$ values of $\mathbf{2 a}-\mathbf{r}$, the retention times of $2 \mathbf{a}-\mathbf{r}$ and the standard samples with $\operatorname{known} \log D$ values were compared under identical UHPLC conditions employing an ODS column. ${ }^{14-16}$ Although all the peptides possess the same planar structure, the numbers of $\log D$ varied significantly, from 3.39 to 5.32 (Table 1), where the values of the natural 2c (4.13) and NTA-epimer 2d (4.34) were close to the average. As the amino acid monomers at the same residue numbers of $\mathbf{2 a - r}$ are enantiomeric with the exception of several diastereomeric monomers (OHIle-1 of $\mathbf{2 f} / \mathbf{q}$ and Ile- 6 of $2 \mathbf{i}$ ), the hydrophobicities of most individual monomers are identical. Therefore, the diverse $\log D$ values of $2 \mathbf{a}-\mathbf{r}$ would originate from differences in the entire three-dimensional structure of each compound. ${ }^{17}$ Specifically, the main-chain stereochemistries of $\mathbf{2 a - r}$ would organize the locations and orientations of the hydrophobic side-chains of the molecules, thereby changing the hydrophobic interactions between the peptides and the ODS column. Thus, quantification of the $\log D$ values demonstrated the significant effect of configurational alterations on the hydrophobicity and the molecular shape of this family of compounds.

Next, the cytotoxicities of the synthetic analogues against P388 mouse leukemia cells were assessed using the XTT assay method (Table 1). ${ }^{18}$ The natural isomer $2 \mathrm{c}$ exhibited subnanomolar-level cytotoxicity, with an $\mathrm{IC}_{50}$ value of $0.51 \mathrm{nM}$. Whereas the stereochemical inversion of the C4 of NTA (2d) induced no drastic change in cytotoxicity $\left(\mathrm{IC}_{50}=0.95 \mathrm{nM}\right)$, alteration of the main chain stereochemistry decreased the 


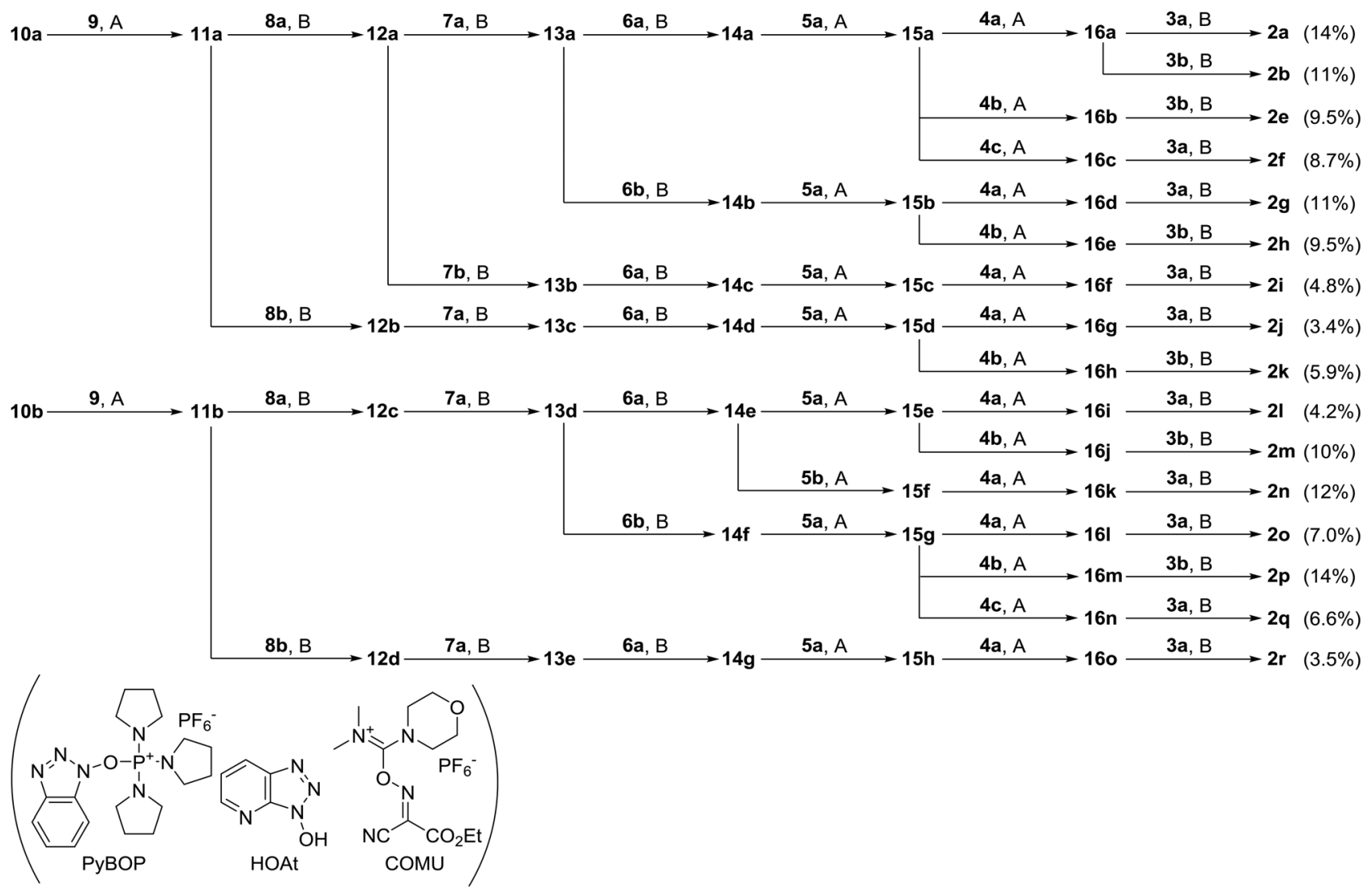

Scheme 1 Syntheses of the analogues $2 a, 2 b$, and $2 e-r$. Overall yields from 9 are given in parentheses. Reagents and conditions: (A) (i) TFA, $\mathrm{CH}_{2} \mathrm{Cl}_{2}$, (ii) PyBOP, HOAt, $i$ - $\mathrm{Pr}_{2} \mathrm{NEt}$, DMF; (B) (i) TFA, $\mathrm{CH}_{2} \mathrm{Cl}_{2}$, (ii) COMU, 2,4,6-collidine, DMF. COMU = (1-cyano-2-ethoxy-2-oxoethylidenaminooxy)dimethylamino-morpholino-carbenium hexafluorophosphate; DMF = N,N-dimethylformamide; HOAt = 1-hydroxy-7-azabenzotriazole; PyBOP = benzotriazol-1-yl-oxytripyrrolidinophosphonium hexafluorophosphate; TFA = trifluoroacetic acid.

Table 1 Hydrophobicities and cytotoxicities of yaku'amide B and its analogues

\begin{tabular}{llc}
\hline Compound & $\log D^{a}$ & $\mathrm{IC}_{50}{ }^{b}(\mathrm{nM})$ \\
\hline 2a & 3.48 & 98 \\
2b & 3.39 & 410 \\
2c & 4.13 & 0.51 \\
2d & 4.34 & 0.95 \\
2e & 3.57 & 620 \\
2f & 3.56 & 450 \\
29 & 3.99 & 92 \\
2h & 3.91 & 530 \\
2i & 3.39 & 300 \\
2j & 4.25 & 9.3 \\
2k & 4.40 & 34 \\
2l & 3.93 & 23 \\
2m & 4.11 & 93 \\
2n & 4.09 & 73 \\
2o & 3.92 & 45 \\
2p & 3.90 & 260 \\
2q & 4.06 & 100 \\
2r & 5.32 & 6.8
\end{tabular}

${ }^{a} \log D$ values were measured by UHPLC methods. ${ }^{b} \mathrm{IC}_{50}$ values were determined from the results of growth inhibition assays (XTT method) performed on P388 mouse leukemia cells. XTT $=33^{\prime}-[1-[($ phenylamino $)-$ carbonyl]-3,4-tetrazolium]bis(4-methoxy-6-nitro)-benzenesulfonic acid hydrate. cytotoxicities of the peptides by $13-(6.8 \mathrm{nM}, 2 \mathrm{r})$ to 1200 -fold $(620 \mathrm{nM}, 2 \mathbf{e})$. Interestingly, $2 \mathbf{j}$ and $2 \mathbf{r}$ that have the identical left half structure (NTA to OHVal-7) to the natural $2 \mathbf{c}$ are the only analogues among $\mathbf{2 a / b} / \mathbf{e}-\mathbf{r}$ with nanomolar-level toxicities. On the other hand, the toxicities of the originally proposed structures $\mathbf{2 a}$ and $\mathbf{2 b}$ were 190 and 800 times weaker than those of $2 \mathbf{c}$, supporting the validity of the revised structure. Overall, the greater potency of $\mathbf{2} \mathbf{c} / \mathbf{d}$ compared to the other fourteen isomers indicated the biological importance of the configurations of the thirteen amino-acid residues of $2 \mathbf{c} / \mathbf{d}$.

To investigate the relationship between the physicochemical and biological properties, the $\log D$ values of the eighteen yaku'amide isomers $2 \mathbf{a}-\mathbf{r}$ were plotted against their $\mathrm{IC}_{50}$ numbers (Fig. 2). Consequently, these two values of the sixteen non-natural analogues $\mathbf{2 a}, \mathbf{2} \mathbf{b}$, and $2 \mathbf{e}-\mathbf{r}$ were found to have a modest linear relationship with the more hydrophobic analogues among $\mathbf{2 a}, \mathbf{2} \mathbf{b}$ and $\mathbf{2 e - r}$ generally exhibiting a higher cytotoxicity. Because of the variable stereostructures of $\mathbf{2 a}, \mathbf{2} \mathbf{2}$ and $\mathbf{2 e - r}$, the cytotoxicities of these non-natural analogues would relate to their non-specific hydrophobic interactions with membranes or biomolecules. In contrast, the naturally occurring isomer 2c and its NTA epimer 2d located well beyond the approximate straight line of the other sixteen ana- 


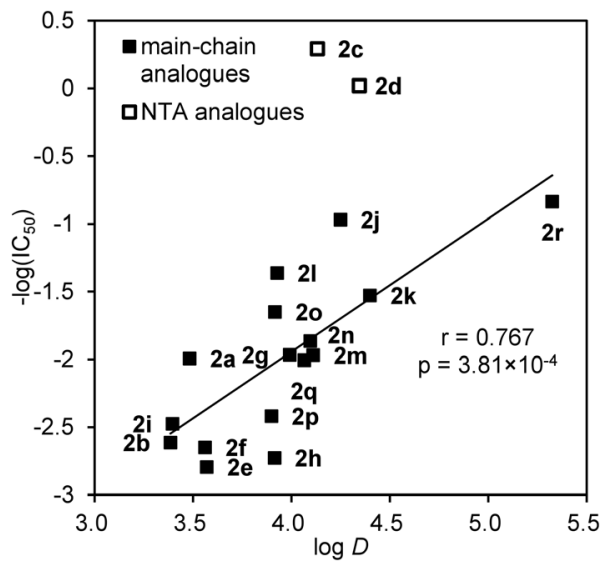

Fig. 2 Plot of $-\log \left(\mid C_{50}\right)$ values against $\log D$ values of $2 a-r$. The black line represents the linear fit of the main-chain analogues $2 a, 2 b$ and $2 \mathrm{e}-\mathrm{r}$. Correlation coefficient $(r)$ and $p$-value are also displayed.

logues. For instance, the cytotoxicities of $\mathbf{2 c}$ and $\mathbf{2 d}$ were significantly higher than those of $\mathbf{2} \mathbf{j}$ and $\mathbf{2 k}$, despite their similar $\log D$ values. Taken together, these data suggested a mode of action of $2 \mathbf{c}$ and $\mathbf{2 d}$ distinct from that of $\mathbf{2 a}, \mathbf{2 b}$ and $2 \mathbf{e}-\mathbf{r}$. Hence, it is likely that peptides $\mathbf{2 c}$ and $\mathbf{2 d}$ display their bioactivities through specific binding to a chiral biomolecule rather than through non-specific hydrophobic interactions. According to this hypothesis, the main chain stereochemistry of 2c and $\mathbf{2 d}$ would fold into the appropriate three dimensional structure, form a complementary surface to a target biomolecule, and thereby cause a potent toxic effect on cancer cells.

\section{Conclusions}

The fourteen analogues $2 \mathbf{e}-\mathbf{r}$ of the naturally occurring yaku'amide B (2c) were newly synthesized in a divergent fashion by assembling stereoisomers of the eight fragments 3-10. The physicochemical and biological properties of the prepared 2e-r were systematically evaluated and analyzed along with the originally proposed structures $2 \mathbf{a} / \mathbf{b}$, the natural $\mathbf{2 c}$, and the $\mathrm{C} 4$ epimer of NTA 2d. Although all the isomers 2a-r share the same planar structure, they showed diverse hydrophobicities and cytotoxicities against P388 mouse leukemia cells. The natural 2c and the NTA-epimer $\mathbf{2 d}$ had average hydrophobicity values $(\log D)$, yet they were 13-1200 times more cytotoxic compared to the sixteen non-natural isomers $\mathbf{2 a}, \mathbf{2} \mathbf{b}$, and $\mathbf{2 e - r}$. The linear correlation between the $\log D$ and $\mathrm{IC}_{50}$ values of the weaker analogues $\mathbf{2 a} / \mathbf{b} / \mathbf{e}-\mathbf{r}$ suggested that the bioactivities of these analogues would be affected through non-specific hydrophobic interactions. On the other hand, the excellent potency of $2 \mathrm{c}$ and 2d would originate from a mode of action distinct from that of the other isomers. Thus, the main chain stereochemistries of $\mathbf{2 c}$ and $2 \mathbf{d}$ would be important for folding into a specific threedimensional structure, which binds to a target biomolecule of the cell to display its cytotoxicity. Detailed biological studies to prove this hypothesis are currently underway in our laboratory.

\section{Acknowledgements}

This research was financially supported by Grant-in-Aids for Scientific Research (A) to M. I., for Young Scientists (B) to T. K., and for Research Activity Start-up to H. I. A fellowship to H. M. from Graduate Program for Leaders in Life Innovation (MEXT) is gratefully acknowledged.

\section{Notes and references}

1 R. Ueoka, Y. Ise, S. Ohtsuka, S. Okada, T. Yamori and S. Matsunaga, J. Am. Chem. Soc., 2010, 132, 17692.

2 (a) S. Yaguchi, Y. Fukui, I. Koshimizu, H. Yoshimi, T. Matsuno, H. Gouda, S. Hirono, K. Yamazaki and T. Yamori, J. Natl. Cancer Inst., 2006, 98, 545; (b) T. Yamori, Cancer Chemother. Pharmacol., 2003, 52, S74; (c) T. Yamori, A. Matsunaga, S. Sato, K. Yamazaki, A. Komi, K. Ishizu, I. Mita, H. Edatsugi, Y. Matsuba, K. Takezawa, O. Nakanishi, H. Kohno, Y. Nakajima, H. Komatsu, T. Andoh and T. Tsuruo, Cancer Res., 1999, 59, 4042.

3 For a recent review on $\alpha, \beta$-dehydroamino acids, see: J. Jiang, Z. Ma and S. L. Castle, Tetrahedron, 2015, 71, 5431.

4 For recent reviews on the application of natural products to drug discovery, see: (a) D. J. Newman and G. M. Cragg, J. Nat. Prod., 2016, 79, 629; (b) M. S. Butler, A. A. B. Robertson and M. A. Cooper, Nat. Prod. Rep., 2014, 31, 1612; (c) J. W.-H. Li and J. C. Vederas, Science, 2009, 325, 161.

5 (a) T. Kuranaga, H. Mutoh, Y. Sesoko, T. Goto, S. Matsunaga and M. Inoue, J. Am. Chem. Soc., 2015, 137, 9443; (b) T. Kuranaga, Y. Sesoko, K. Sakata, N. Maeda, A. Hayata and M. Inoue, J. Am. Chem. Soc., 2013, 135, 5467.

6 For synthetic studies on yaku'amides from other groups, see: (a) Z. Ma, J. Jiang, S. Luo, Y. Cai, J. M. Cardon, B. M. Kay, D. H. Ess and S. L. Castle, Org. Lett., 2014, 16, 4044; (b) C. J. Saavedra, A. Boto and R. Hernández, Org. Lett., 2012, 14, 3788; (c) Z. Ma, B. C. Naylor, B. M. Loertscher, D. D. Hafen, J. M. Li and S. L. Castle, J. Org. Chem., 2012, 77, 1208.

7 For reviews on Cu-mediated enamide formation, see: (a) T. Kuranaga, Y. Sesoko and M. Inoue, Nat. Prod. Rep., 2014, 31, 514; (b) G. Evano, C. Theunissen and A. Pradal, Nat. Prod. Rep., 2013, 30, 1467; (c) D. S. Surry and S. L. Buchwald, Chem. Sci., 2010, 1, 13; (d) D. Ma and Q. Cai, Acc. Chem. Res., 2008, 41, 1450; (e) G. Evano, N. Blanchard and M. Toumi, Chem. Rev., 2008, 108, 3054.

8 For recent accounts on the total synthesis and biological evaluation of peptidic natural products from our laboratory, see: antillatoxin. (a) M. Inoue, Proc. Jpn. Acad., Ser. B, 2014, 90, 56; polytheonamide B. (b) H. Itoh and M. Inoue, Acc. Chem. Res., 2013, 46, 1567.

9 See the ESI $\dagger$ for details.

10 J. Coste, D. Le-Nguyen and B. Castro, Tetrahedron Lett., 1990, 31, 205.

11 L. A. Carpino, J. Am. Chem. Soc., 1993, 115, 4397. 
12 A. El-Faham, R. S. Funosas, R. Prohens and F. Albericio, Chem. - Eur. J., 2009, 15, 9404.

13 (a) D. Gaspar, A. S. Veiga and M. A. R. B. Castanho, Front. Microbiol., 2013, 4, 294; (b) V. Teixeira, M. J. Feio and M. Bastos, Prog. Lipid Res., 2012, 51, 149.

14 OECD, Test No. 117. Partition Coefficient (n-octanol/water), HPLC Method, OECD Guidelines for the Testing of Chemicals, Section 1, OECD Publishing, Paris, 2004.

$15 \log D$ values were measured in the presence of $0.05 \%$ TFA as a buffer, because protonation of the CTA moiety under acidic conditions was required for the reliability and reproducibility of UHPLC analyses of the analogues. Detailed conditions are described in the ESI. $\dagger$

16 For recent examples, see: (a) A. Hayata, H. Itoh, S. Matsutaka and M. Inoue, Chem. - Eur. J., 2016, 22, 3370; (b) H. Itoh, S. Matsutaka, T. Kuranaga and M. Inoue, Tetrahedron Lett., 2014, 55, 728; (c) L. Ferrins, M. Gazdik,
R. Rahmani, S. Varghese, M. L. Sykes, A. J. Jones, V. M. Avery, K. L. White, E. Ryan, S. A. Charman, M. Kaiser, C. A. S. Bergström and J. B. Baell, J. Med. Chem., 2014, 57, 6393; (d) P. P. Bose, U. Chatterjee, I. Hubatsch, P. Artursson, T. Govender, H. G. Kruger, M. Bergh, J. Johansson and P. I. Arvidsson, Bioorg. Med. Chem., 2010, 18, 5896; (e) E. H. Kerns, L. Di, S. Petusky, T. Kleintop, D. Huryn, O. McConnell and G. Carter, J. Chromatogr., B, 2003, 791, 381.

17 For a recent related example, see: Y. Huang, L. Pan, L. Zhao, C. T. Mant, R. S. Hodges and Y. Chen, Biomed. Chromatogr., 2014, 28, 511.

18 (a) D. A. Scudiero, R. H. Shoemaker, K. D. Paull, A. Monks, S. Tierney, T. H. Nofziger, M. J. Currens, D. Seniff and M. R. Boyd, Cancer Res., 1988, 48, 4827; (b) N. W. Roehm, G. H. Rodgers, S. M. Hatfield and A. L. Glasebrook, J. Immunol. Methods, 1991, 142, 257. 